\title{
MICROSTRUCTURE AND PLASTIC PROPERTIES OF Mg-Li ALLOYS SMELTED IN VACUUM INDUCTION FURNACES AFTER HOT WORKING
}

\begin{abstract}
The paper analyses the characteristics of plasticity and microstructure of magnesium alloys with lithium meant for hot plastic working with different lithium content. The alloys were prepared in conditions of vacuum smelting. Achieved ingots were subject to hot extrusion. Tests on Gleeble simulator were conducted to assess the susceptibility of tested alloys to plastic forming in conditions of hot plastic working. For tested alloy the activation energy was marked for hot plastic deformation and plasticity characteristics in function of Zener-Hollomon parameter. After the analysis of the influence of temperature on the deformability of tested alloys it was stated that the alloy containing $8 \% \mathrm{Li}$ (LAZ831) has better susceptibility to plastic treatment than alloy containing $4 \% \mathrm{Li}$ (LAZ431), but higher than in case of classic magnesium alloys - AZ31.

Keywords: magnesium-lithium alloy, research of plasticity, activation energy, hot working microstructure
\end{abstract}

\section{Introduction}

Magnesium alloys with lithium are new generation of ultra-light alloys for application in construction elements. Addition of lithium significantly improves the low susceptibility to plastic working of magnesium alloys. Overview of literature connected with magnesium alloys with lithium [1-6] shows that conducted tests concentrate on optimisation of the chemical composition by introduction of additional elements which improve the resistance of alloy and its temperature stability in improvement of vacuum smelting technology and casting and by the application of heat-plastic treatment for forming the structure and mechanical properties. Preparation of such type of material, however, can be difficult in terms of smelting and casting. The paper presents technological aspects of producing alloys of the type Magnesium-Lithium meant for plastic treatment. The subjects of tests were multi-component alloys of magnesium with aluminium and zinc, containing $4 \%, 8 \%$ of lithium. The previous papers determined the influence of smelting atmosphere (vacuum, argon) as well as the type of melting pots for smelting and their influence on the course of metallurgical process [7]. It was stated that it is beneficial to smelt the tested alloys in solid melting pots made of $\mathrm{Al}_{2} \mathrm{O}_{3}$, in argon atmosphere and then to cast them into graphite moulds [7]. Structure of $\mathrm{Mg}$ and $\mathrm{Li}$ alloys is not strictly dependent on casting parameters, which are casting temperature and the rate of cooling in casting mould. Due to that fact it is possible to i.e. elevate the temperature of casting in order to provide the required castability of alloys without the danger of grain growth and their change of type from equiaxial to columnar. The paper tested alloys containing $4 \%$ and $8 \% \mathrm{Li}$. Binary alloys $\mathrm{Mg}-\mathrm{Li}$ are characterised with low mechanical properties and that is why Al, $\mathrm{Zn}$ and Mn were used in the character of alloy elements. The amounts of the elements corresponded with the required content of those elements in the composition of classic alloy AZ31. Those elements form solid solutions and intermetallic phases which improve the resistance of the magnesium alloys. Created alloys were subject to hot extrusion and their basic mechanical properties were later determined. In the paper, the basic plastic properties of the created alloys were defined with the use of Gleeble3800 simulator. Determination of the plasticity characteristics is important due to the fact that the type of crystallographic network and low number of slip systems in magnesium eliminates the possibility of cold plastic forming of this group of materials. Conducted tests allowed for preparation of technology of $\mathrm{Mg}$-Li alloys production with the application of vacuum metallurgy and further processes of plastic treatment with the use of extrusion method.

\section{Material for tests}

The paper presents analysis of magnesium alloys with lithium content of 4 and $8 \%$ of mass with additions of $\mathrm{Al}, \mathrm{Zn}$ and $\mathrm{Mn}$, the chemical composition of which is shown in Table 1.

\footnotetext{
SILESIAN UNIVERSITY OF TECHNOLOGY, INSTITUE OF METALS TECHNOLOGY, KATOWICE, POLAND

** VŠB - TECHNICAL UNIVERSITY OF OSTRAVA OSTRAVA, CZECH REPUBLIC

\# Corresponding author: eugeniusz.hadasik@polsl.pl
} 
TABLE 1

Chemical composition of investigated alloys, [\% mass]

\begin{tabular}{|c|c|c|c|c|c|}
\hline \hline Alloy & Li & Al & Zn & Mn & Mg \\
\hline AZ31 & - & 3.1 & 0.71 & 0.2 & rest \\
\hline LAZ431 & 4 & 2.8 & 0.61 & 0.2 & rest \\
\hline LAZ831 & 8 & 2.9 & 0.45 & 0.2 & rest \\
\hline
\end{tabular}

\section{Technology of smelting and casting}

Smelting was conducted with the use of single-compartment, induction, laboratory vacuum furnace VSG 02 by Balzers Company, in which the compartment of melting and casting is at the same time the compartment for moulds and casting moulds. Technically pure magnesium, lithium and aluminium 3N8 $(99.98 \% \mathrm{Al})$ were used as charging components. Smelting was conducted in argon atmosphere under pressure of 650 Tor to minimise the process of evaporation of charging components. The temperature of smelting was about $700 \div 720^{\circ} \mathrm{C}$, smelting time was about $5 \mathrm{~min}$. which, taking into account the intensive, electro-dynamic mixing of the bath with the use of rotary current, was enough to achieve the total homogenisation of liquid alloy. The temperature of casting alloys was about $630 \div 660^{\circ} \mathrm{C}$, depending on lithium content. Alloys were gravity casted into cold graphite moulds and the ingots were achieved with sizes of $ø 40 \times 80 \mathrm{~mm}$. The ingots are characterised with the homogenous, fine-grained structure and no casting defects are present in them besides the commonly present shallow contraction cavity (Fig. 1).

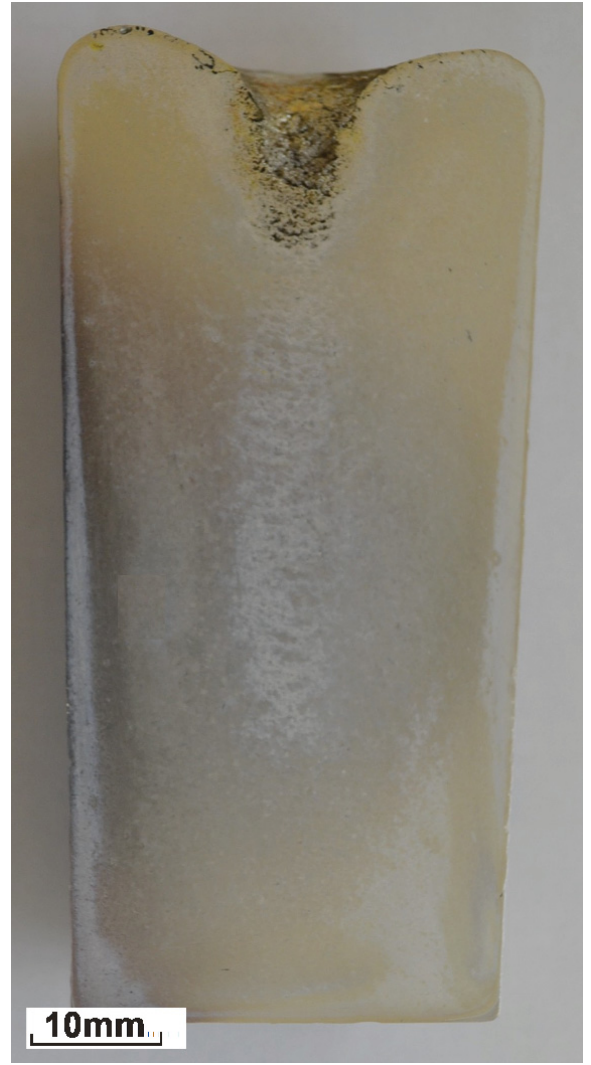

Fig. 1. Cross-section of ingot from LAZ441 alloy

\section{Deformability tests}

Extrusion process was conducted on a hydraulic press at Silesian University of Technology. Before extrusion the ingots were heated to $400^{\circ} \mathrm{C}$. The rods with diameter of $10 \mathrm{~mm}$ were achieved (deformation $\varepsilon=2.5$ ). Compression tests were conducted to mark the plasticity characteristics on a Gleeble 3800 simulator in temperature range from room temperature (RT) to $400^{\circ} \mathrm{C}$. Compression test was conducted after heating the sample to deformation temperature with heating rate of $3{ }^{\circ} \mathrm{C} / \mathrm{s}$, and holding down the sample in this temperature for 300s. The applied strain rates were $0.01,0.1$ and $1.0 \mathrm{~s}^{-1}$ and the given value of real strain equalled 0.8 . The registered values were calculated on the dependency of flow stress $\left(\sigma_{p}\right)$ from strain $(\varepsilon)$ for tested alloys.

In order to mathematically describe the influence of the deformation process parameters on the properties the ZenerHollomon $Z$ was calculated in a dependency:

$$
Z=\dot{\varepsilon} \exp \left(\frac{Q}{R \cdot T}\right)
$$

on the basis of activation energy $Q$ marked in a constitutive equation:

$$
\dot{\varepsilon}=C \cdot \exp \left(-\frac{Q}{R \cdot T}\right) \cdot\left(\sin h\left(\alpha \sigma_{p p}\right)\right)^{n}
$$

where: $C, \alpha, n$-coefficients, $\sigma_{p p}$ - maximum value of flow stress.

Activation energy was marked with the use of a program ENERGY 4.0 [8]. Peak flow stress $\sigma_{p p}$ in function of parameter $Z$ was calculated from a transformed dependency (3):

$$
\sigma_{p}=\frac{1}{\alpha} \cdot \arg \sin h\left(\sqrt[n]{\frac{Z}{C}}\right)
$$

Deformation (strain) $\varepsilon_{p}$ which corresponds with maximum flow stress in function of parameter $Z$ was marked from exponential function [9]:

$$
\varepsilon_{p}=U \cdot Z^{W}
$$

where: $U$ and $W$ are material constants.

\section{Tests results}

The microstructures of $\mathrm{Mg}-\mathrm{Li}$ samples after casting in comparison to AZ31 one is shown in Fig. 2. After casting the structure of alloy LAZ441 is not homogenous a. There are clearly visible areas of eutectic in this structure, which are situated in the interdendritic areas of the a phase (Fig. 2b). On the basis of previous X-ray tests it was found that the eutectic is a mixture of phases $\delta+\lambda$ [10]. Hexagonal phase $\delta$ is a terminal solid solution of aluminium in magnesium but it is a brittle phase which is difficult to deform. Phase $\lambda$ is a terminal solid solution of aluminium in lithium with regular body-centred cubic network and with good plastic properties [11]. In alloy LAZ831 structure, in comparison with alloy LAZ431 there is an additional presence of phase $\beta$ which is a terminal solid solution of magnesium in 


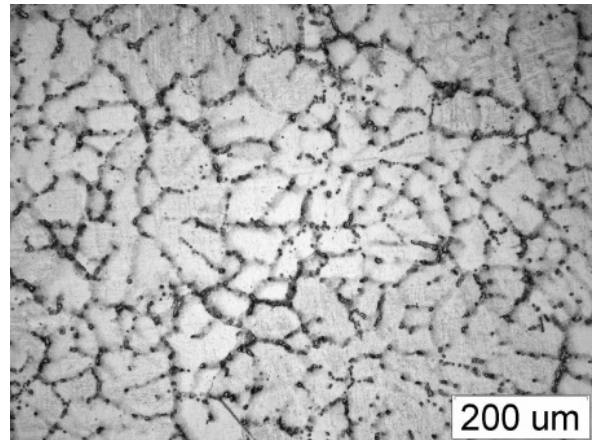

a)

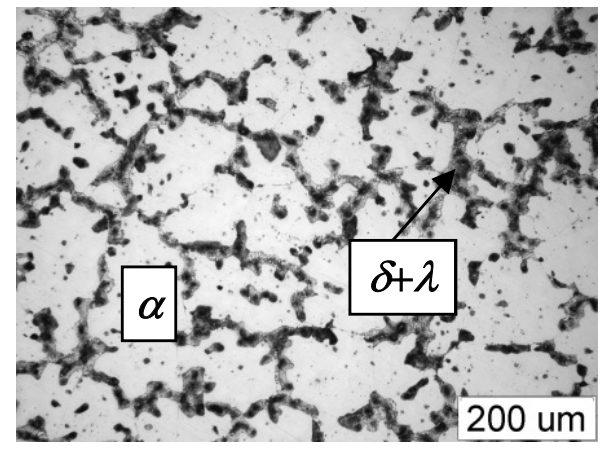

b)

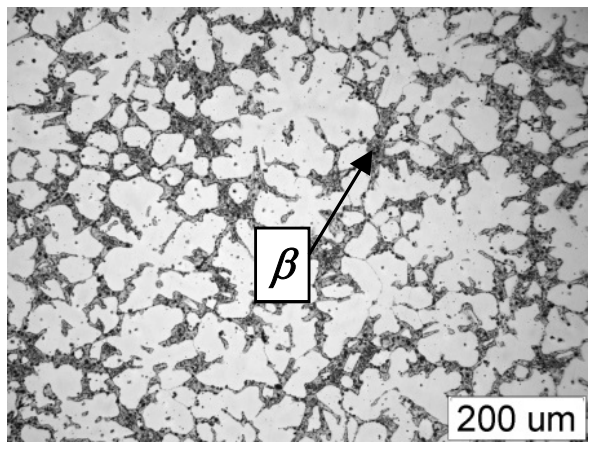

c)

Fig. 2. Microstructure of investigated alloys after hot casting: a - AZ31 alloy, b - LAZ431 alloy, c - LAZ841 alloy

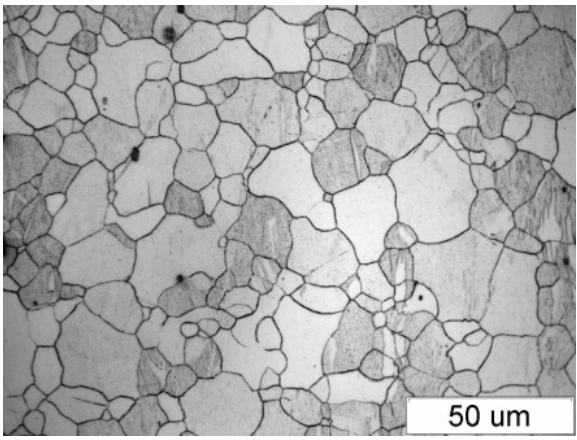

a)

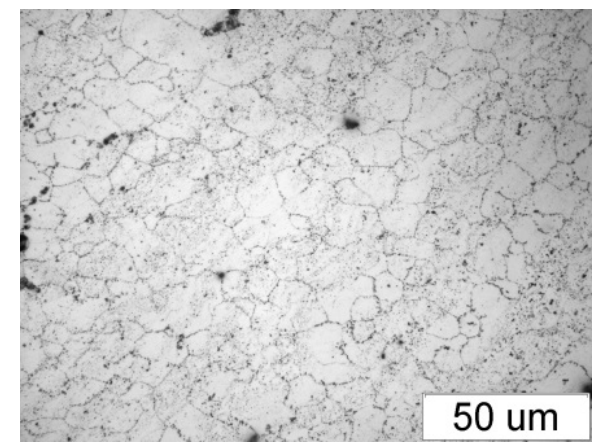

b)

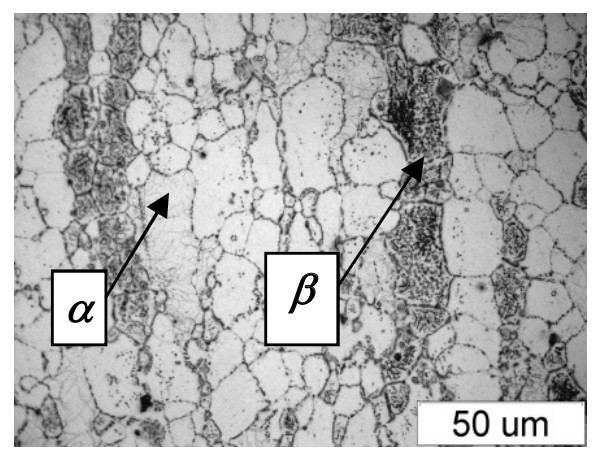

c)

Fig. 3. Microstructure of investigated alloys after hot extrusion at $400^{\circ} \mathrm{C}$ : a - AZ31 alloy, b-LAZ431 alloy, c-LAZ841 alloy

lithium visible on metallographic sections as dark areas (Fig. 2c). The results were compared with classic magnesium alloy AZ31 in which the solid solution of aluminium in magnesium dominates. Tested alloys after extrusion are characterised with fine-grained microstructure. The microstructures of samples after extrusion are shown in Fig. 3.

Comparison of the tests results of mechanical properties for binary alloys Mg-Li and alloys AZ31, LAZ441 and LAZ841 after extrusion process shows the improvement of strength and decrease of plasticity which can be seen in values of ultimate tensile strength (UTS) and elongation to failure (A) (Table 2). In magnesium alloys addition of lithium ecrease of strength and increase of plasticity.

TABLE 2

Mechanical properties of magnesium-lithium alloy after hot working

\begin{tabular}{|c|c|c|}
\hline \hline Alloy & UTS [MPa] & A [\%] \\
\hline Mg & 170 & 15 \\
\hline AZ31 & 250 & 12 \\
\hline Mg4Li & 158 & 32 \\
\hline LAZ431 & 215 & 18 \\
\hline Mg8Li & 105 & 41 \\
\hline LAZ831 & 179 & 35 \\
\hline
\end{tabular}

The redundancy curves of flow stress to stress achieved in compression tests show a differentiated character of the course of the process depending on the deformation temperature and the lithium content in the alloy (Figs. 4-6). Summary results of process parameters of peak stress and corresponding deformation are shown in Table 3. It is clearly visible that the addition of $4 \%$ lithium leads to the improvement of deformability $\left(\varepsilon_{f}\right)$ by $\varepsilon=0.1$ in comparison with alloy without lithium (AZ31) (Fig. 4,5). Further addition of lithium (to 8\%) increases the deformability even more (Fig. 6). Classic magnesium alloys achieve bigger deformability in temperature range from $200 \div 225^{\circ} \mathrm{C}$ because additional slip planes become active. Tested magnesium alloy AZ31 achieves the given deformation $(\varepsilon=0.8)$ without failure in a temperature of $200^{\circ} \mathrm{C}$ and in case of alloy LAZ441 in a temperature of only $175^{\circ} \mathrm{C}$ and in case of alloy LAZ841 in temperature of $150^{\circ} \mathrm{C}$. Together with the increase of the lithium content the character of the flow curves changes (in the initial stage of strengthening), especially in the lower temperatures where in initial stage they have a characteristic hollow shape. It proves the decrease of influence of twinning as a dominant mechanism of deformation and beneficial influence of this element on the susceptibility to plastic forming. The rate of deformation is also important, alloy AZ31 when deformed with bigger rate $1 \mathrm{~s}^{-1}$ can be upset without failure to the assumed deformation of $\varepsilon=0.8$, in temperature of $250^{\circ} \mathrm{C}$, whereas alloy LAZ841 in temperature of $200^{\circ} \mathrm{C}$.

Marked values of activation energy $\mathrm{Q}$ in temperature range of plastic treatment proves that alloy AZ31 has higher activation energy of plastic deformation $\left(Q=174.3 \mathrm{KJ} \cdot \mathrm{mol}^{-1}\right)$ in comparison with alloys containing lithium $\left(Q=151.3 \mathrm{KJ} \cdot \mathrm{mol}^{-1}\right)$. 


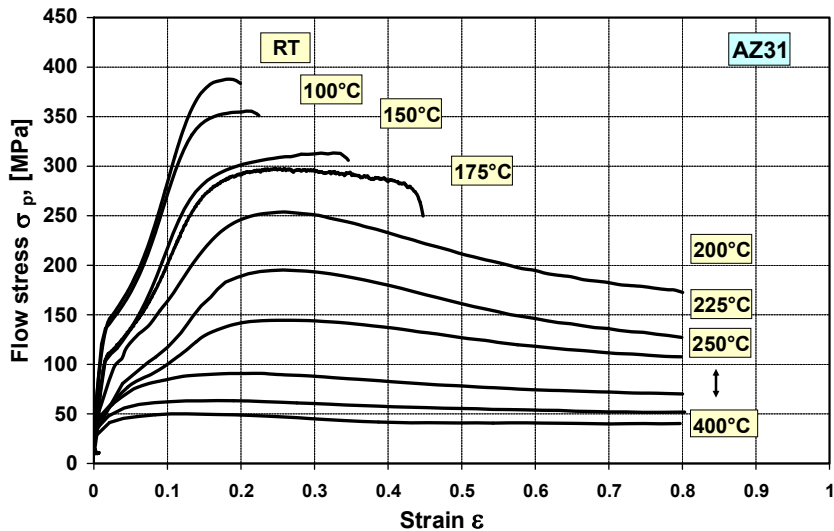

Fig. 4. Flow stress $\left(\sigma_{p}\right)$ in strain $(\varepsilon)$ function for AZ31 after compression in temperature from $\mathrm{RT}^{\circ} \mathrm{C}$ to $400^{\circ} \mathrm{C}$ with a strain rate $0.1 \mathrm{~s}^{-1}$

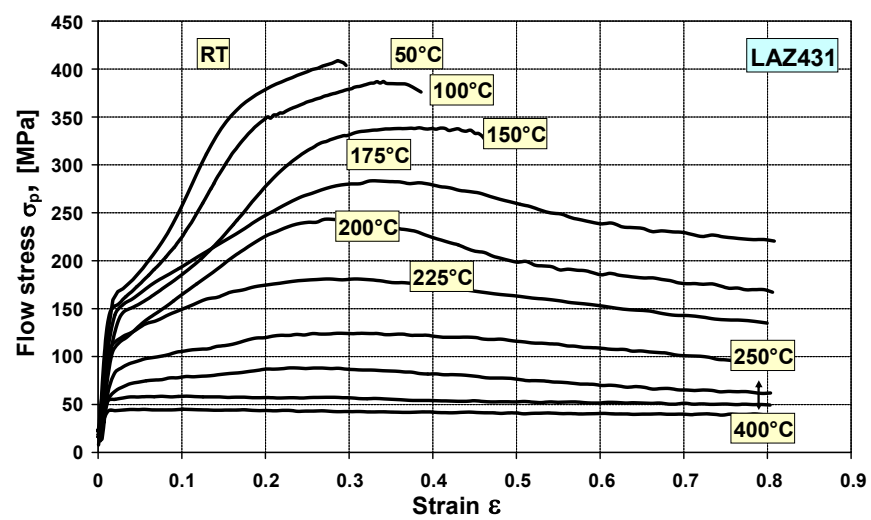

Fig. 5. Flow stress $\left(\sigma_{p}\right)$ in strain $(\varepsilon)$ function for LAZ431 after compression in temperature from RT to $400^{\circ} \mathrm{C}$ with a strain rate $0.1 \mathrm{~s}^{-1}$

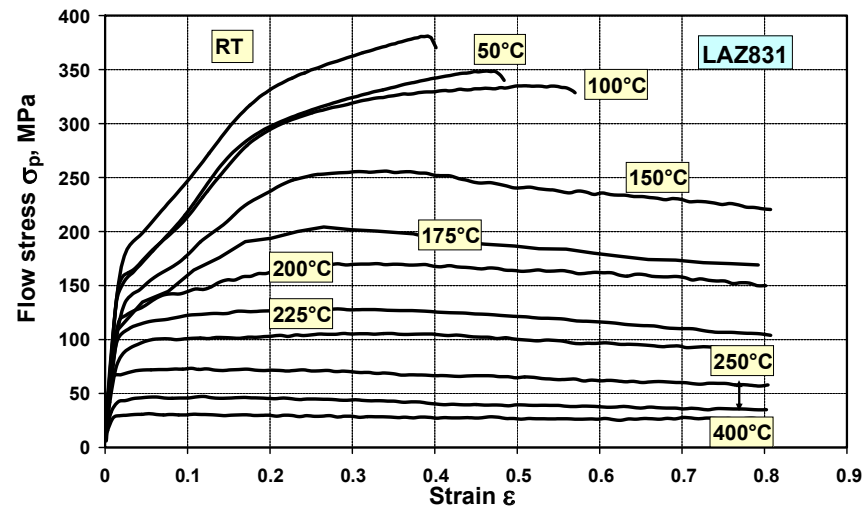

Fig. 6. Flow stress $\left(\sigma_{p}\right)$ in strain $(\varepsilon)$ function for LAZ831 after compression in temperature from RT to $400^{\circ} \mathrm{C}$ with a strain rate $0.1 \mathrm{~s}^{-1}$

Increasing the $\mathrm{Li}$ content leads to decrease of the value of material constant $\left(Q=138.1 \mathrm{KJ} \cdot \mathrm{mol}^{-1}\right)$. A good consistence was found of the calculated values of maximum flow stress $\sigma_{p p}$ and strain $\varepsilon_{p}$ deformation from Zener-Hollomon parameter on the basis of equations (3) and (4) with experimental data (Fig. 7,8). It is clearly visible that the alloys containing lithium show higher sensitivity of strain $\varepsilon_{p}$ on change of process parameters in comparison with alloy AZ31 (Fig. 8). For small values of parameter Z (high temperature, small strain rate) they quickly reach maximum on the flow curve.

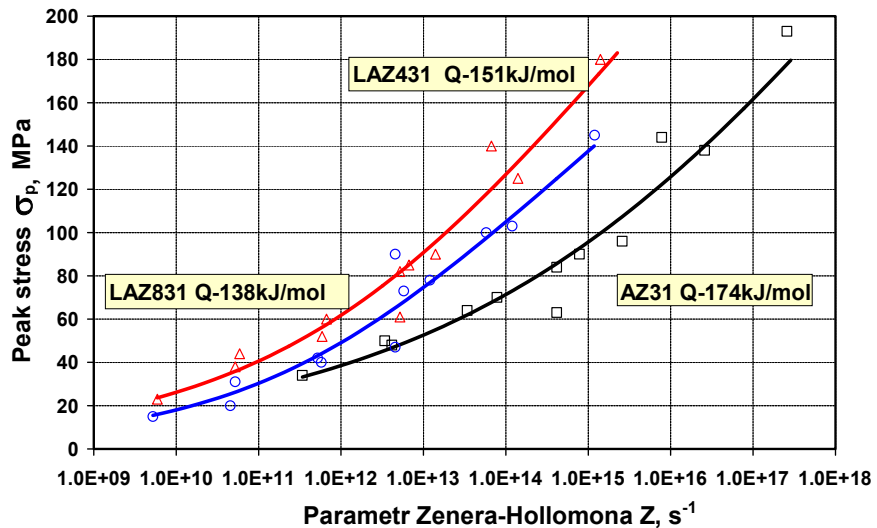

Fig. 7. Dependency peak flow stress $\sigma_{p p}$ from Zener-Hollomon parameter $\mathrm{Z}$ for investigated alloys

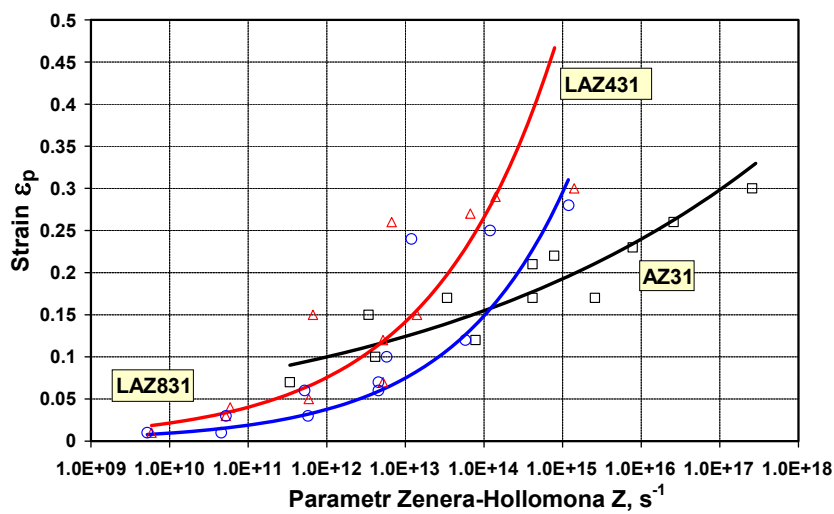

Fig. 8. Dependency of strain $\varepsilon_{p}$ from Zener-Hollomon parameter $\mathrm{Z}$ for investigated alloys

Results of microhardness measurement with the use of Vickers HV0.2 method are shown in Fig. 9. In samples after extrusion the decrease of hardness is observed together with the increase of lithium content. In samples which were upset from alloy AZ31 there is a significant increase of hardness observed after deformation in room temperature to a temperature of $200^{\circ} \mathrm{C}$. In samples with $4 \% \mathrm{Li}$ content the decrease of hardness is observed in $175^{\circ} \mathrm{C}$, and in alloy with content of $8 \% \mathrm{Li}$ in temperature of $150^{\circ} \mathrm{C}$.

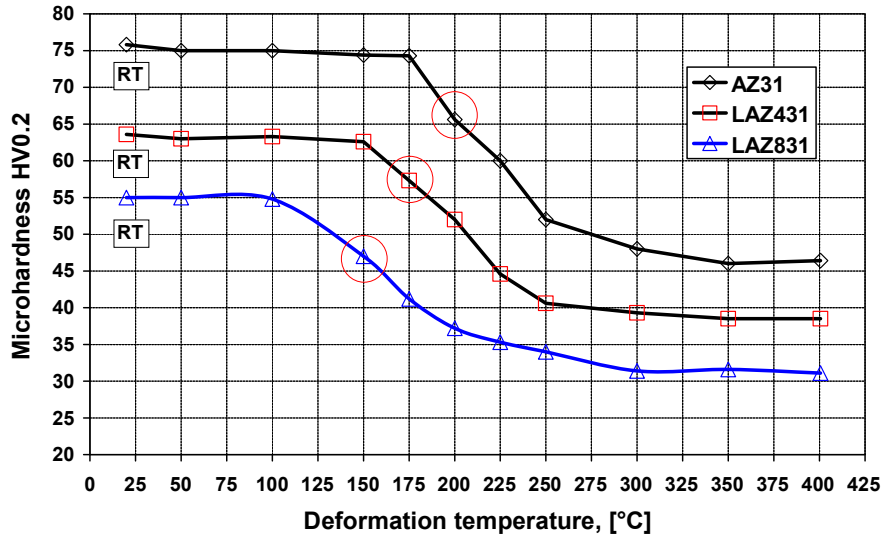

Fig. 9. Influence of deformation temperature on microhardness HV0.2 of tested alloys 
Peak flow stress $\left(\sigma_{p p}\right)$ and deformation $\left(\varepsilon_{p}\right)$ depending on temperature $T$ and strain rate $(\dot{\varepsilon})$ for investigated alloys

\begin{tabular}{|c|c|c|c|c|c|c|c|c|c|c|}
\hline \multirow{2}{*}{$\begin{array}{c}\text { Temperature } \\
T\left[{ }^{\circ} \mathbf{C}\right]\end{array}$} & \multirow{2}{*}{$\begin{array}{c}\text { Strain } \\
\text { rate } \\
\dot{\varepsilon}\left[\mathrm{s}^{-1}\right]\end{array}$} & \multicolumn{3}{|c|}{ AZ31 } & \multicolumn{3}{|c|}{ LAZ431 } & \multicolumn{3}{|c|}{ LAZ831 } \\
\hline & & $\begin{array}{c}\sigma_{p p} \\
{[\mathbf{M P a}]}\end{array}$ & $\varepsilon_{p}$ & $\varepsilon_{f}$ & $\left.\begin{array}{c}\sigma_{p p} \\
{[\mathrm{MPa}}\end{array}\right]$ & $\varepsilon_{p}$ & $\varepsilon_{f}$ & $\sigma_{p p}[\mathrm{MPa}]$ & $\varepsilon_{p}$ & $\varepsilon_{f}$ \\
\hline RT & 0.1 & 390 & - & 0.20 & 410 & - & 0.32 & 410 & - & 0.40 \\
\hline \multirow{3}{*}{150} & 0.01 & 285 & 0.24 & 0.41 & 297 & 0.35 & 0.65 & 220 & 0.54 & - \\
\hline & 0.1 & 310 & 0.28 & 0.35 & 325 & 0.27 & 0.40 & 250 & 0.40 & - \\
\hline & 1 & 345 & 0.35 & 0.28 & 356 & 0.48 & 0.32 & 276 & 0.46 & 0.64 \\
\hline \multirow{3}{*}{175} & 0.01 & 340 & 0.22 & 0.56 & 260 & 0.34 & - & 225 & 0.26 & - \\
\hline & 0.1 & 300 & 0.28 & 0.45 & 252 & 0.26 & - & 200 & 0.30 & - \\
\hline & 1 & 280 & 0.32 & 0.32 & 212 & 0.22 & 0.61 & 180 & 0.34 & - \\
\hline \multirow{3}{*}{200} & 0.01 & 220 & 0.24 & - & 224 & 0.22 & - & 185 & 0.42 & - \\
\hline & 0.1 & 250 & 0.28 & - & 242 & 0.27 & - & 160 & 0.40 & - \\
\hline & 1 & 272 & 0.31 & 0.6 & 263 & 0.29 & - & 172 & 0.44 & - \\
\hline \multirow{3}{*}{225} & 0.01 & 205 & 0.22 & - & 165 & 0.19 & - & 110 & 0.40 & - \\
\hline & 0.1 & 200 & 0.27 & - & 175 & 0.24 & - & 128 & 0.30 & - \\
\hline & 1 & 210 & 0.29 & 0.72 & 142 & 0.26 & - & 131 & 0.27 & - \\
\hline \multirow{3}{*}{250} & 0.01 & 96 & 0.21 & - & 92 & 0.15 & - & 78 & 0.24 & - \\
\hline & 0.1 & 138 & 0.30 & - & 128 & 0.29 & - & 103 & 0.25 & - \\
\hline & 1 & 193 & 0.26 & - & 184 & 0.31 & - & 145 & 0.28 & - \\
\hline
\end{tabular}

Microstructure tests show that in alloys deformed in lower temperature a big number of deformation twinning occurs which can then be explained in low deformability of alloys with smaller content of lithium (Fig. 10a). In higher temperature the process of recrystallization occurs and either the very fine recrystallization on the boundaries of elongated primary grains (Fig. 10b) or a fully recrystallized structure is observed (Fig. 10c).

\section{Summary}

Designing the technology of plastic processing of construction elements requires precise determination of influence of the process parameters on the plasticity and microstructure of alloys. The benefits of magnesium-lithium alloys are shown in many papers [1-6,12]. However, it should be underlined that the disadvantage of the alloys containing lithium is the decrease of resistance of magnesium alloys as well as decrease of corro- sion resistance, particularly when the amount of this element is bigger. Products with better set of mechanical properties than the ones achieved with the use of casting can be achieved with the use of plastic processing. The paper presents the results of plasticity tests and microstructure of $\mathrm{Mg}$ alloys with different lithium content which additionally had alloy elements $(\mathrm{Al}, \mathrm{Zn}$, $\mathrm{Mn}$ ) in the amount required for classic alloy AZ31. Binary alloys $\mathrm{Mg}$-Li have relatively low mechanical properties. Suggested alloy additions increase the resistance properties by solid solution strengthening and precipitation strengthening. Magnesium alloys below temperature of $200-225^{\circ} \mathrm{C}$ are characterised with low deformability due the low number of active skid systems. Their number increases during deformation to above $225^{\circ} \mathrm{C}$. In deformed magnesium alloys, especially in lower temperature, the aberration from classic course of flow stress occurs in the deformation function. The shape of the curve is initially hollow which is connected with intense twinning. The twins block the movement of the dislocation which leads to their concentra-

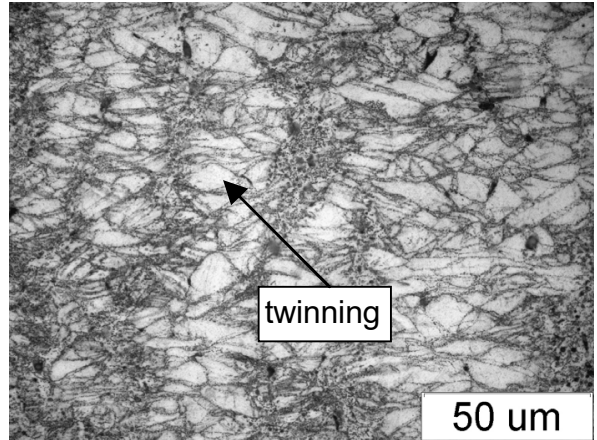

a)

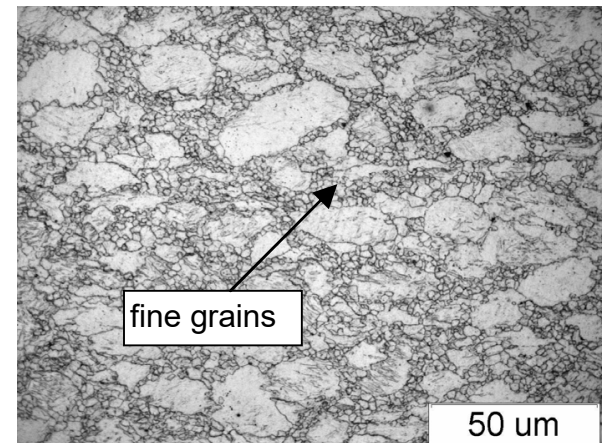

b)

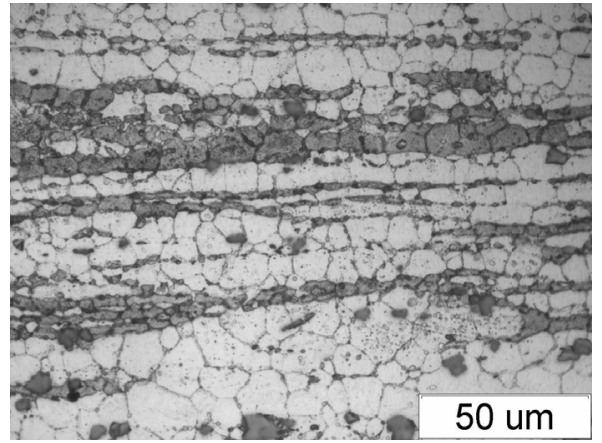

c)

Fig. 10. Microstructure of investigated alloy after compression test : a: LAZ431 $-T=175^{\circ} \mathrm{C}$ with a rate $\dot{\varepsilon}=0.1 \mathrm{~s}^{-1}, \mathrm{LAZ} 431-T=300^{\circ} \mathrm{C}$ with a rate $\dot{\varepsilon}=1 \mathrm{~s}^{-1}, \mathrm{LAZ} 831-T=300^{\circ} \mathrm{C}$ with a rate $\dot{\varepsilon}=0.1 \mathrm{~s}^{-1}$ 
1432

tion and the location of the deformation and as a consequence to quick cracking. In alloys this effect decreases by $4 \% \mathrm{Li}$ and significantly by $8 \% \mathrm{Li}$ content. With $8 \%$ lithium content there is a big amount of ductile phase b-Li present in the alloy. Alloys containing lithium show better deformability in comparison with conventional magnesium alloys. Together with the increase of the lithium content in the alloy, the temperature in which the sample can be deformed with application of big draft without cracking, decreases. It was proved that with the increase of the amount of lithium in the alloy the flow stress decreases in comparison with classic alloys. Achieved data shows that tested alloys can be shaped with the use of plastic working and it is possible to lower the temperature of plastic working of $\mathrm{Mg}-\mathrm{Li}$ alloys. It can also be confirmed by microstructure tests and measurements of microhardness. Lithium aids the decrease of temperature in which the process of recovery occurs and that fact positively influences the decrease of hardness in lower temperature and improvement of deformability. It is as well confirmed by the literature data [3], lithium influences the increase of the stacking fault energy (SFE) of alloys and at the same time the susceptibility to dynamic recovery. Dependence of maximum flow stress $\sigma_{p p}$ and deformation $e_{p}$ in function of Zener-Hollomon parameter for tested alloys can be described as power function, similarly to steel alloys of other metals $[8,12]$. Calculated values of activation energy are lower than in case of alloy AZ31 and decrease together with the increasing amount of lithium. Conducted tests allowed for determination of the approximate parameters of plastic working process for tested alloys created with the use of technology of vacuum metallurgy and casting. Results of tests will help in designing technology of manufacturing construction elements which could serve as light substitutes of currently used materials.

\section{Acknowledgements}

This work was supported by Polish Ministry for Science and Higher Education under internal grant BK264/RM2/2016 for Institute of Metals Technology, Silesian University of Technology, Poland.

\section{REFERENCES}

[1] M.V. Kral, B.C. Muddle, Materials Science and Engineering A 460-461, 227-232 (2007).

[2] H. Dong, F. Pan, J.D. Bin, D. Jiahong, Q. Yang, Journal of Alloys and Compounds 590, 233-240 (2014).

[3] T. Al-Samman, Acta Mater. 57, 2229-2242 (2009).

[4] T. Wang, M. Zhang, R. Wu, Materials Letters 62, 1846-1848 (2008).

[5] L.W. Mackenzie, M. Pekguleryuz, Materials Science and Engineering A 480, 189-197 (2008).

[6] T. Chang, J. Wang, Ch. Chu, S. Lee, Materials Letters 60, 32723276 (2006).

[7] T. Mikuszewski, Metalurgija 53(4), 588-590 (2014).

[8] I. Schindler, J. Boruta, Utilization Potentialities of the Torsion Plastometer, Silesian University of Technology, 1998.

[9] I. Kliber, I. Schindler, Steel Research International 60, 82-91 (1989).

[10] A. Białobrzeski, K. Saja, K. Hubner, Archives of Foundry Engineering 7, 11-16 (2007).

[11] D. Kuc, E. Hadasik, J. Mizera, T. Mikuszewski, Solid State Phenomena 212, 11-14 (2014).

[12] D. Kuc, G. Niewielski, J. Cwajna, Materials Characterization 56, 318-324 (2006). 